\title{
Industrial Automation using Modern Controls, Monitoring, Data Logging and Development of Training Facility in College
}

\author{
Sneha S. Mhetraskar \\ Department of Electrical Engineering \\ Bharti Vidyapeeth (Deemed to be University) College \\ of Engineering Pune, India
}

\author{
Prof. Swapnil A. Namekar \\ Department of Electrical Engineering \\ Bharti Vidyapeeth (Deemed to be University) College \\ of Engineering Pune, India
}

\begin{abstract}
Industrial automation (IA), decreases the need for human sensory, human energy and cost. Now a day's as per the industrial requirement, the highly growth in the sensors, control and automation technologies like control systems i.e. Programmable Logic Controller (PLC) and Supervisory Control and Data Acquisition (SCADA).Historians for data collections and Easy analysis, Reports Generations, other development Towards IIoT Industries 4.0 concepts and Implementations. These are performing a most important role in the automation of industries and increasing the Demand of This kind of knowledge Engineers in the industries. The Basic Introduction and Hands on Project Facilities development in a college by using different types of software's as well as hardware tools, to get the brief idea to the upcoming students.
\end{abstract}

\section{Keywords_-Plc; Hmi; Energy Meter; Induction Motor; Vfd; Im} Starting Method; Data Logging \& Reporting

\section{INTRODUCTION}

Industrial automation involves usage of advanced control strategies like, modern control hardware cascade controls devices like PLC, sensors \& other instruments for sensing the control variables \& signal conditioning equipment's to connect the signals to the control devices, Drives other smart significant final control devices, standalone computing systems, communication systems, alarming, Reporting, Data logging and HMI systems. HMI's offers the facilities like, displaying the information on computer screens and other displays, logging the results in the database, giving alarm signal, etc. It uses technologies like SCADA (Supervisory Control and Data Acquisition) and other visual based technologies.

As we have visited many industries and the electricity board, near by the Pune. We understand that the Complexities, flexibility, remote operations, data logging, monitoring, reporting, and easy to handling of machines and the factories or the business in the more cost effective manner with fast meet the market demands. The Development in the Electronics and Computer sector, Use of modern concept in the Automation

Demand is increased. Hence, in the industries uses of smart instruments, automations, communications, are used. To meet the Diversified business demand in the global manufacturing, Setups are setup in the varies locations, Realtime and fast, authenticate data and the information is on demand. Similarly, demand of sophisticated and intelligent, Fast Grasping of this upcoming Industrial Automation knowledge Engineers required in the Industries. By this concept we have discussed with Dr. Deepak Banker and Prof. Swapnil Namekar to develop and implement the Modern Industrial Automation Projects Training Setups for Students in the colleges to get the knowledge and hands-on before going to the Industries at the educations level.

\section{BLOCK DIAGRAM AND SYSTEM COMPONENT DESCRIPTION}

A. Plc

PLC means Programmable Logic Controllers. The PLC are used to control automated systems in industries. The PLC are one of the most advanced and simplest forms of control systems which are now replacing hard wired logic relays at a large scale. The PLC is heart of the system. In project Nexgenie NG16DL plc used. The ladder logic implemented in Codesys Software. In that, PLC 8 input and 8 outputs supports. The PLC was interfaced with HMI by using RS-232 protocol and Energy Meter by using RS-485 protocol.

\section{B. $\mathrm{Hmi}$}

A Human-Machine Interface (HMI) is a user interface that which is connected to a person to a machine and, system/ device. The HMI is most commonly used in an industrial process. As per industrial settings the HMIs can be used for: Visually display data, Track production time, trends, and tags, Monitor machine inputs and outputs, etc. In project the Exor make HMI was used \& JMobile suit is the development software used.

C. $\quad \boldsymbol{V} f d$

Always in the industry, need arises for controlling the speed of a 3-phase induction motor. The motor drives are able to efficiently control motor speed and improve machine automation save energy The drive is in its variable frequency drive (VFD series is designed to meet specific application as per requirement. A VFD can be used to vary speed, direction and other parameters of a 3-phase induction motor. In project YASAKWA make VFD is used. The rating of VFD is $1.5 \mathrm{KW}$. The VFD is used for control the speed of Induction Motor.

\section{Induction Motor and Its Starting Methods}

The AC induction motor is widely used in applications requiring constant speed operation. The induction motor is cheaper and easier to maintain and compared to other alternatives. The induction motor is made up of the 
stator/stationary windings and the rotor. The stator is consists of series of wire windings of very low resistance and it is permanently attached to the motor frame. The voltage and a current is applied to the stator winding terminals and a magnetic field is developed in the windings, the stator windings are arranged, the magnetic field appears to synchronously rotate electrically around the Inside of the motor housing. The rotor having a number of thin bars e.g. aluminum bar and mounted in a laminated cylinder. The $\mathrm{Al}$ bars are arranged horizontally and parallel to the rotor shaft. At the ends of the rotor- the bars are connected together with a "shorting ring." The rotor and stator are separated by an air gap which allows free rotation of the rotor. The magnetic field generated in the stator, it induces an EMF in the rotor bars. In turn, a current is produced in the rotor bars, shorting ring as well as another magnetic field are induced in the rotor with an opposite polarity of that in the stator. The magnetic field and revolving in the stator will the produces torque which will "pull" on the field in the rotor and establish rotor rotation.

A 3-phase induction motor is self-starting motor (Theoretically). 3-phase induction motors have a starting method not to provide a starting torque at the rotor due to the following reasons: Reduce heavy starting currents and prevent motor from overheating and Provide overload and no-voltage protection. In project I have done the 3 ways to start the Induction motor using PLC.

- Induction Motor control using DOL starter.

- Induction Motor control using VFD through Analogue Output.

- Induction Motor control using forward and reverse control.

\section{E. Energy Meter}

The Schneider Make Energy Meter is used for measurement of different parameters like voltage, current, power, etc. The EM6436H model is used. In this module the in build RS-485 port is there which is communicated with PLC.

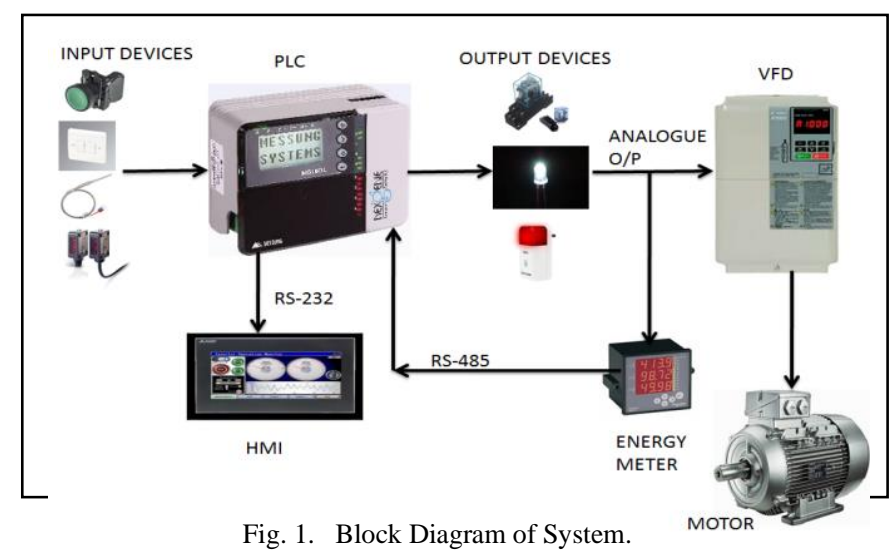

In "Fig. 1," this model all the inputs are connected to PLC and the information will be send to the plc through it. The Output devices are connected to the plc outputs and driven from the input sensors and from plc program. PLC outputs will give the Command to Frequency Drive and Drive will vary the frequency and the Voltage to the Induction Motor, The speed will be vary from the Drive. Energy meter is connected to the Plc through Rs458 Communication and the
Data/Parameter will be read by the PLC Through this communications. HMI will be connected to the PLC and information will be display or the commands will be giving for the operations from it. The parameters like voltage, current, KW and KVA are read by the load manager which is interfaced with the PLC. The PLC is interfaced with HMI. In the existing system Nexgenie PLC is used also Energy meter, CTs is installed in panel and HMI screen is display on front of the panel. There are three parameter displays on HMI screen these are SLD, PARAMETER and SETTING by clicking SLD, SLD will appear on screen by clicking PARAMETER tab all parameter are display like voltage, current, power etc. and by clicking SETTING tab we can change the threshold value. Once the parameters for threshold are set, the CPU of PLC will continuously monitor the parameters though the energy meters connected as input to PLC.

\section{Electrical Drawing}

The EPLAN software is used for design the electrical drawing. In that we show the single line diagram of electrical components and show the VFD connections with mains. In "Fig. 2," shows the single line diagram of VFD connections. And "Fig. 3," shows the input and output connection with PLC and Energy Meter connections with CT's.

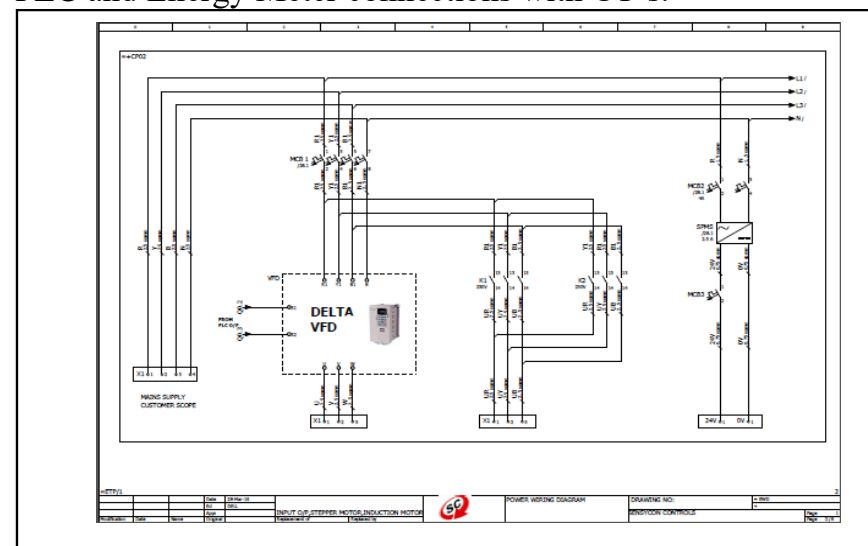

Fig. 2. Electrical Single Line Diagram Of VFD Connections.

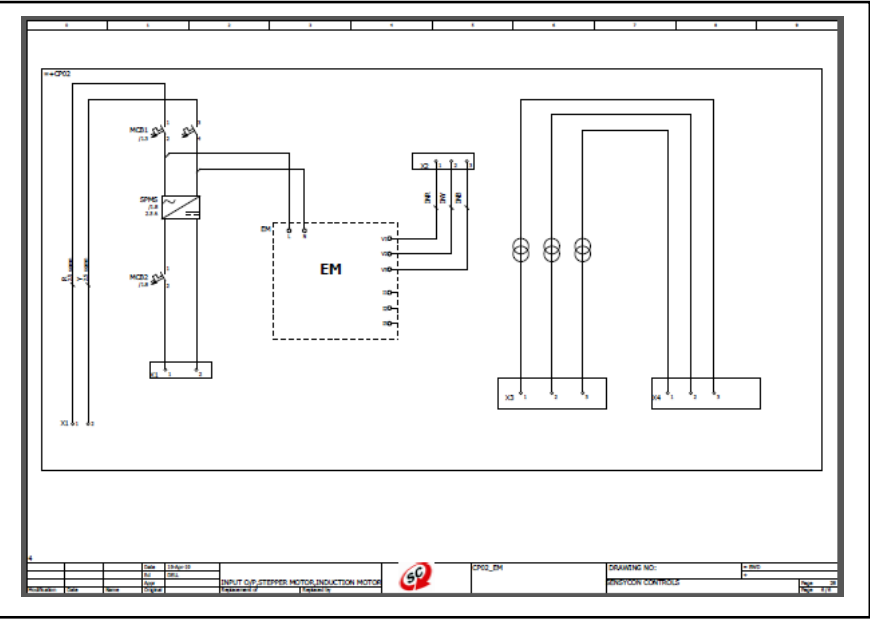

Fig. 3. Electrical Single Line Diagram Of Energy Meter Connections

\section{Hardware Assembly}

In project the following materials are used which is listed. 
- Programmable Logic Controller-NG16DL

- Human Machine Interface-ESAMRT07M

- Energy Meter-EM6436H

- Variable Frequency Drive - J1000

- Electrical hardware And Switchgear

- Induction Motor - 3 Phase, 0.75 kw,400Volts.

- Current Transformer

- Panel

"Fig. 4," Shows the various devices of input and output, energy meter and current transformer . In that panel the input output is connected through plc. The energy meter is connected to CT's. In "Fig. 5," consist of Nexgine PLC, Exor HMI, VFD, Contactors, Smps etc. We have done the Control panel and operating panel is separately, because the students can

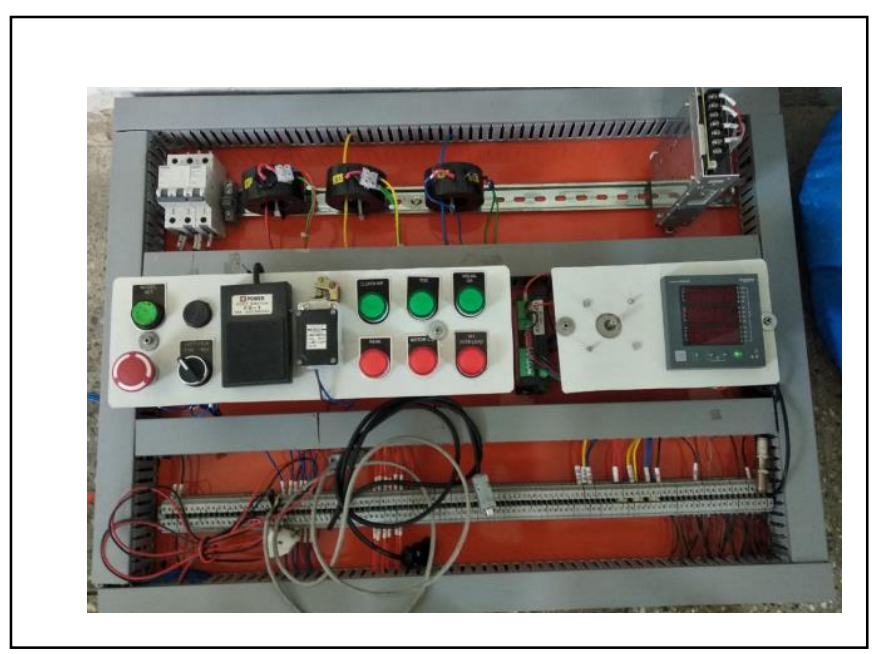

Fig. 4. Panel Assembely for Input-Output Connection.

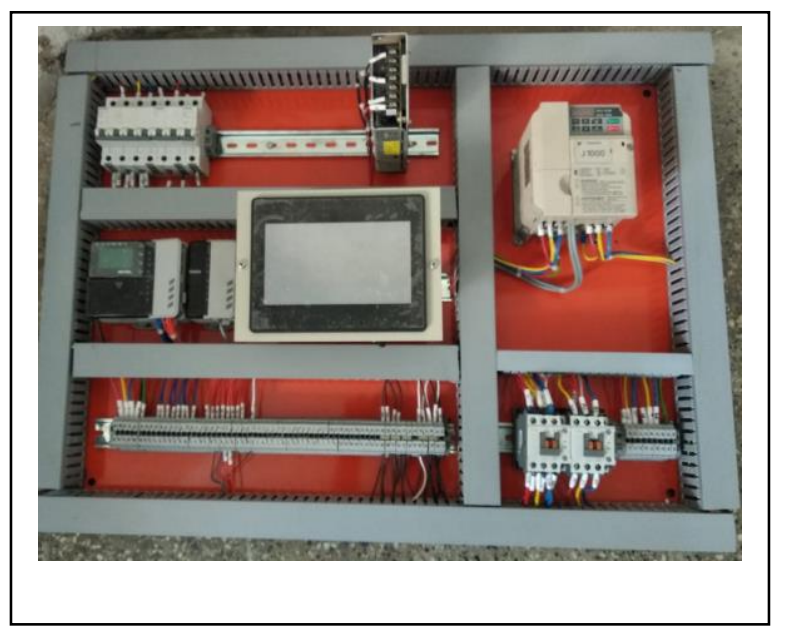

Fig. 5. Panel Assembely for PLC Connections.

\section{Development of PLC Program}

The PLC program is developed in Codesys V2.3 software. In that program we did the ladder programming. In "Fig. 6,"

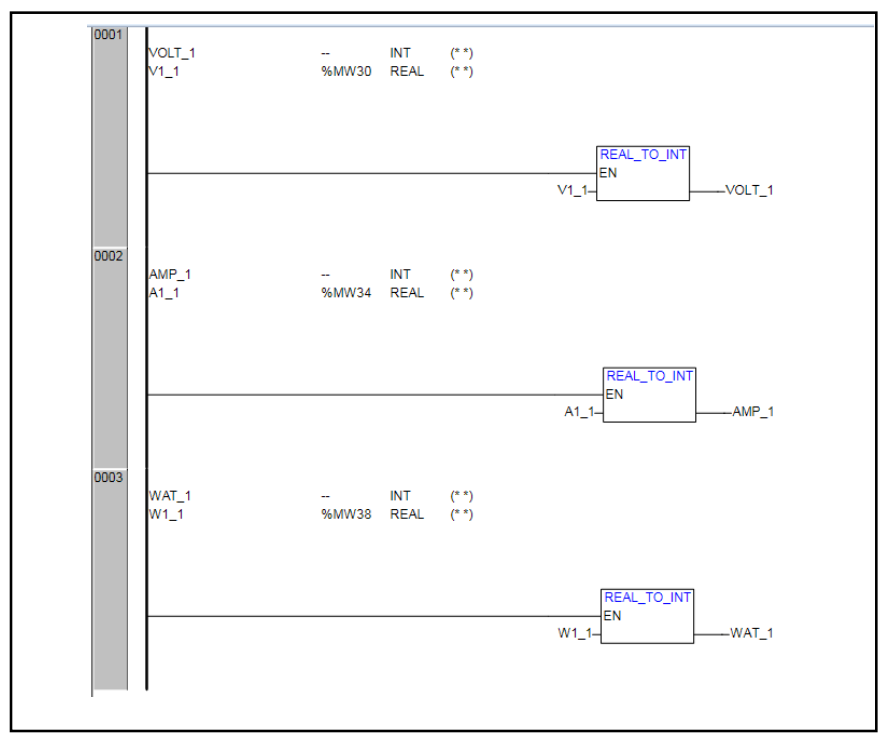

Fig. 6. Laader Logic of Conversion of Real value to Integer value.

Shows ladder logic of conversion of real value data to integer data while in "Fig. 7," shows the hmi operations for start stop the vfd. In "Fig. 8," shows the logic of input output testing and in "Fig. 9," shows the analog output scaling logic with speed vary command is used.

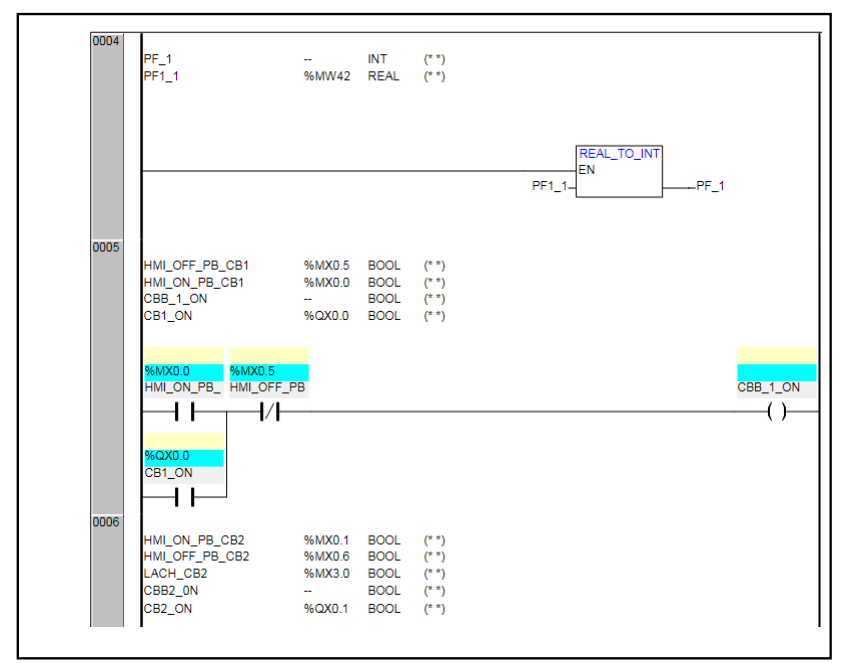

Fig. 7. Laader Logic Start-Stop Operations of Induction Motor.

handle easily. 


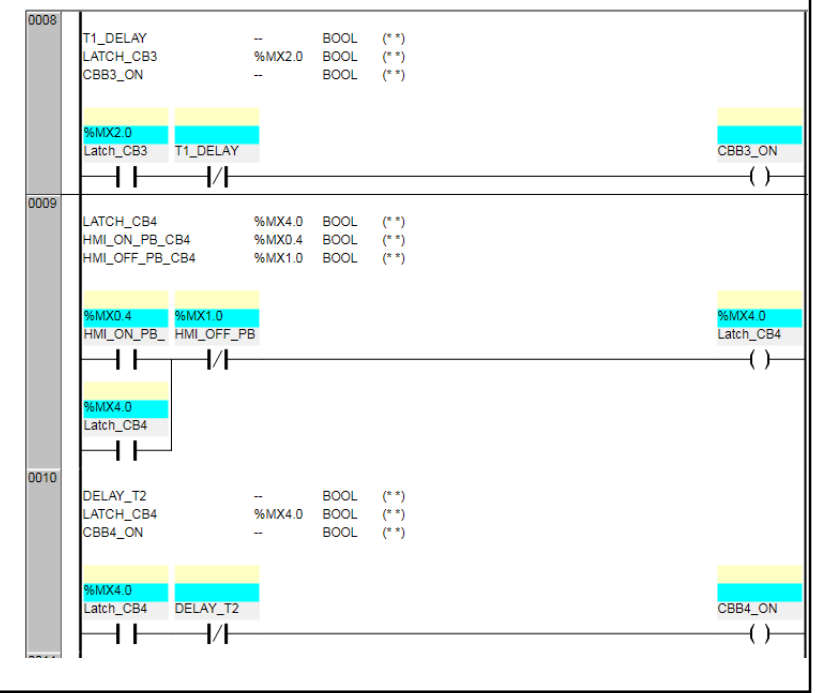

Fig. 8. Laader Logic of Input-Output Testing.

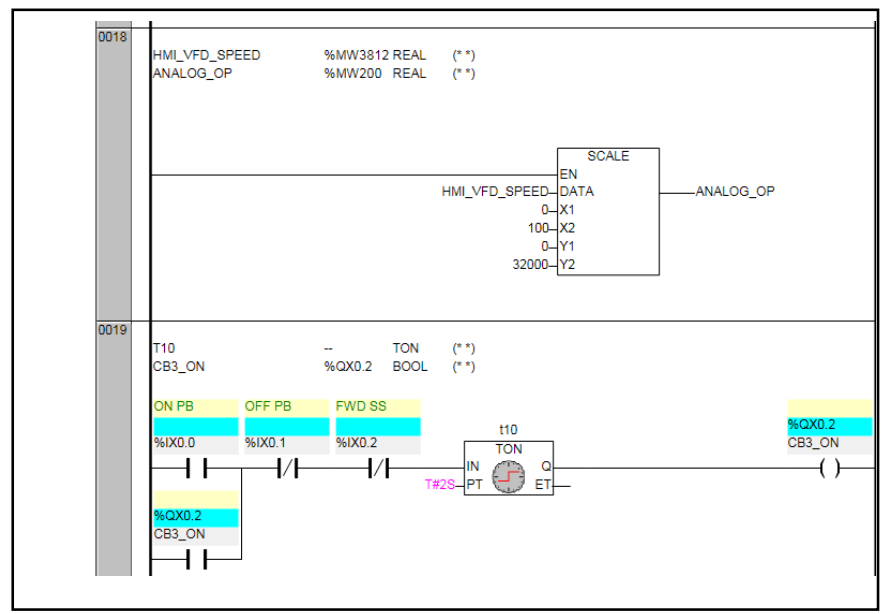

Fig. 9. Laader Logic Analog Scaling and Speed vary using Vfd.

\section{Development of HMI Program}

HMI programming is done in J-mobile suit software. In that we develop the screens for operations. In "Fig. 10," the input-output status shows which helpful for fault diagnosis. In "Fig. 11," the vfd operations and induction motor speed indicates. In "Fig. 12," the energy meter parameters display on screen like voltage, current, power, power factor, frequency.

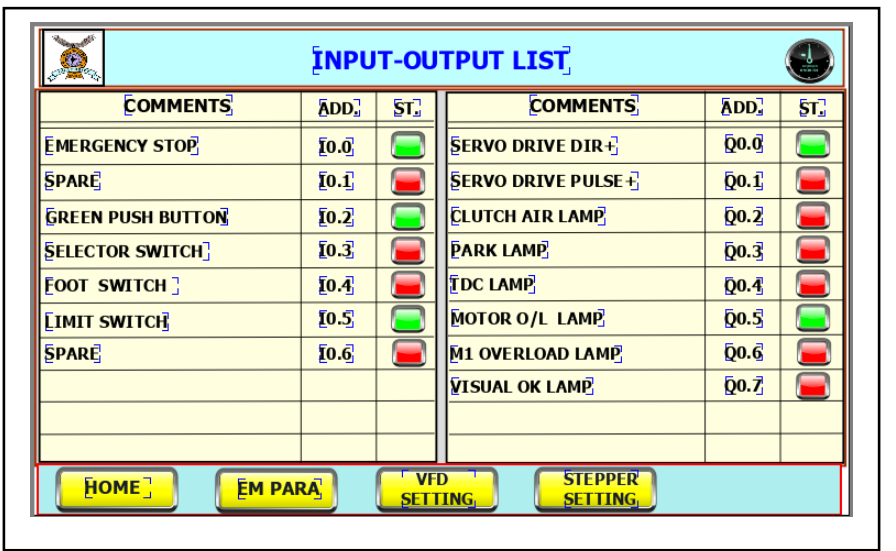

Fig. 10. HMI Screen of IO Status

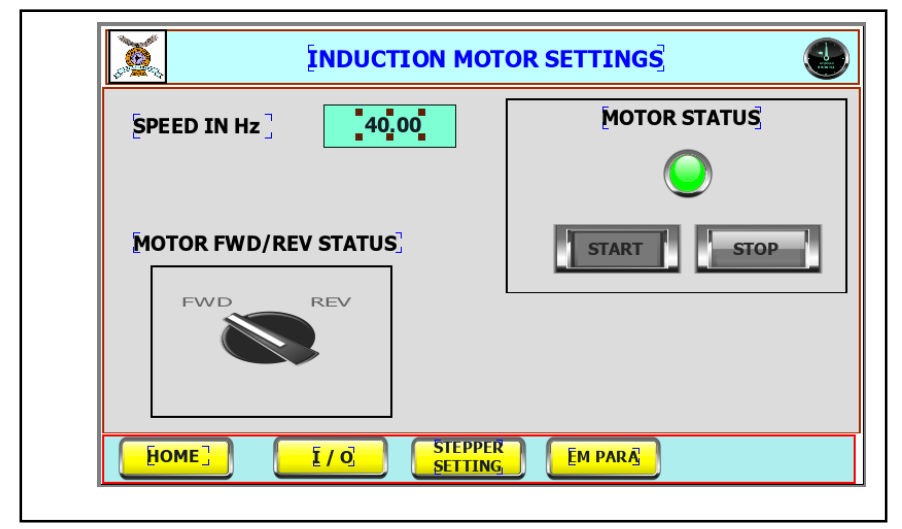

Fig. 11. HMI Screen of VFD Operations

\begin{tabular}{|c|c|c|c|}
\hline \multicolumn{4}{|c|}{ ENERGY METER PARAMETER ${ }_{\lrcorner}^{\urcorner}$} \\
\hline \multicolumn{2}{|c|}{ [PARAMETERS } & \multicolumn{2}{|c|}{ PARAMETERS } \\
\hline [VR PHASE] & 99999.00 [0LTS] & REACTIVE POWER] & 99999.00 KVAR] \\
\hline [VY PHASE] & 99999.00 [NOLTS & VVRY PHASE & 99999.00 ํoLTS \\
\hline [VB PHASE] & 99999.00 ㅁoLTS & VYB PHASE' & 99999.00 ํoLTS \\
\hline R CURRENT $_{\lrcorner}^{\top}$ & 99999.00 ĀMP & VBRR PHASE] & 99999.00 otTS \\
\hline$\left[\begin{array}{l}Y \\
\text { CURRENT }\end{array}\right.$ & $99999.00 \mathrm{~A} M \mathrm{~A}_{]}$ & POWER FACTOR' & 99999.00 \\
\hline B CURRENT & 99999.00 AMP & EREQUENCY & $99999.00 \quad \bar{H} Z_{]}^{7}$ \\
\hline 'ACTIVE POWER] & 99999.00 [NATT & & \\
\hline APPERENT POWER] & 99999.00 [ू & & \\
\hline$\left[\mathrm{HOME}_{\lrcorner}^{\top}\right.$ & {$[/ 0$} & $\begin{array}{c}\text { VFD } \\
\text { SEIIING } \\
\end{array}$ & \\
\hline
\end{tabular}

Fig. 12. HMI Screen of Energy Parameter Monitoring 


\section{Data Logging \& Reporting}

The data logging is important part in Industries. This is done for future analysis. In "Fig. 13," the screen shot of energy meter logged data parameters in excel format. In that the 3 phase voltages, 3 phase currents, power factor, frequency and 3 phase powers recorded. We can check data in any particular date. For analysis purpose we did the data log.

\begin{tabular}{|c|c|c|c|c|c|c|c|c|c|}
\hline 4 & A & B & C & D & E & $\mathrm{F}$ & G & $\mathrm{H}$ & I \\
\hline 1 & Date & Time & VR PHASE- & - VY PHASE- & VB PHASE- & R CURREN & J Y CURREN & B CURREN & NPIN W-1 \\
\hline 2 & \#\#\#\#\#\# & $12: 27: 20$ & 230.6865 & 226.6355 & 228.5364 & $2.00 \mathrm{E}-17$ & 1.543297 & 2.662969 & 919.0203 \\
\hline 3 & \#\#\#\#\#\# & 12:27:21 & 230.7051 & 226.6355 & 228.597 & 2.00E-17 & 1.543297 & 2.663748 & 919.2084 \\
\hline 4 & \#\#\#\#\#\#\# & $12: 27: 22$ & 230.7381 & 226.6696 & 228.6276 & $52.00 E-17$ & 1.543445 & 2.664346 & 919.4232 \\
\hline 5 & \#\#\#\#\#\# & $12: 27: 23$ & 230.7381 & 226.6864 & 228.6594 & 2.00E-17 & 1.543882 & 2.664346 & 919.6585 \\
\hline 6 & \#\#\#\#\#\# & $12: 27: 24$ & 230.7577 & 226.6962 & 228.6982 & $2.00 \mathrm{E}-17$ & 1.543852 & 2.664626 & 919.8068 \\
\hline 7 & \#\#\#\#\#\# & $12: 27: 25$ & 230.7739 & 226.7084 & 228.7299 & $2.00 \mathrm{E}-17$ & 1.543431 & 2.664412 & 919.7638 \\
\hline 8 & \#\#\#\#\#\#\# & $12: 27: 26$ & 230.7859 & 226.7196 & 228.7481 & I. 2.00E-17 & 1.543332 & 2.665387 & 920.0334 \\
\hline 9 & \#\#\#\#\#\#\# & 12:27:27 & 230.7878 & 226.7343 & 228.7717 & $2.00 \mathrm{E}-17$ & 1.543385 & 2.665798 & 920.2397 \\
\hline 10 & \#\#\#\#\#\# & $12: 27: 28$ & 230.8028 & 226.7466 & 228.8006 & $2.00 E-17$ & 1.543191 & 2.665813 & 920.2397 \\
\hline 11 & \#\#\#\#\#\# & $12: 27: 29$ & 230.8133 & 226.7505 & 228.8006 & $2.00 \mathrm{E}-17$ & 1.542834 & 2.665813 & 920.2905 \\
\hline 12 & \#\#\#\#\#\# & $12: 27: 30$ & 230.8073 & 226.7505 & 228.8353 & $2.00 E-17$ & 1.542834 & 2.665469 & 920.1999 \\
\hline 13 & \#\#\#\#\#\# & $12: 27: 31$ & 230.8073 & 226.7646 & 228.8599 & $2.00 \mathrm{E}-17$ & 1.543164 & 2.665342 & 920.2798 \\
\hline 14 & \#\#\#\#\#\# & $12: 27: 32$ & 230.8145 & 226.7858 & 228.8822 & $2.00 \mathrm{E}-17$ & 1.542983 & 2.665111 & 920.3278 \\
\hline 15 & 5\#\#\#\#\#\# & $12: 27: 33$ & 230.8181 & 226.8064 & 228.9079 & $2.00 E-17$ & 1.543303 & 2.665259 & 920.558 \\
\hline 16 & "\#\#\#\#\#\# & $12: 27: 34$ & 230.8254 & 226.8214 & 228.9277 & 2.00E-17 & 1.543163 & 2.665202 & 920.6186 \\
\hline 17 & 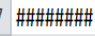 & $12: 27: 35$ & 230.8303 & 226.8408 & 228.9462 & $2.00 E-17$ & 1.543472 & 2.665429 & 920.8184 \\
\hline 18 & B \#\#\#\#\#\# & $12: 27: 36$ & 230.8225 & 226.8573 & 228.9649 & $2.00 \mathrm{E}-17$ & 1.54337 & 2.665417 & 921.0901 \\
\hline 19 & 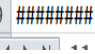 & $12: 27: 37$ & 230.825 & 226.8644 & 229.0018 & $32.00 E-17$ & 1.543421 & 2.665417 & 921.090 \\
\hline
\end{tabular}

Fig. 13. Screen Shot of Data Logging Format In Excel Sheet

\section{RESULTS}

All the Operations are controlled from the HMI like speed control of Induction Motor using Reverse / Forward control by using contactors, DOL starting of Induction Motor and Speed control using VFD through PLC analog output .System Start /Stop operations done from the HMI through PLC. Energy Meter Parameters are Monitored like Voltage, Current and Power on the HMI. Now This All the Demo Projects are ready for the practice and hands on to the all Upcoming students in the college and helps them to the better understanding, this project gives the overview of industrial Automations used in the Industries. After Implementing and practiced all above experiments we are able to handle and introduced to the present Industrial Automation System. We found from above the automation can make the Engineering is more efficient, less time consuming, flexible, more useful and interactive to the operation point of view. Also it is more accurate and can act more safety and protective to the equipment / machinery / process. Hence Automation can be widely accepted in a industries and its need for the economical productivity.

\section{A. Conclusion}

In this project we implement the hardware as well as programming; we have deal with the following topics:

1) It shows that the control and IT both are used in automation systems to realize one or more of its functionalities and also Control Technology is used for operation of the individual machines and equipment.IT is used for coordination, management and optimized operation of overall project.

2) It shows that Automation increases the profitability in many different ways by decreasing the labor, and material and also energy requirements.

3) By using this techniques we can improve the quality and productivity. Industrial automation is improves the reliability of production. So that industries get the accuracy and precision automation using less energy resources.

4) By using the intelligent techniques in Industrial Automation, the production process done better human friendly and reduce the complexity of machine.

\section{B. Future Scope}

The automation industry is facing new type of challenges like that information security management. The major part of the challenge comes from the diffusion of new ICT technology into the field. Solutions in the field show a strong trend of convergence towards common ICT solutions, especially to IP-based communication and de-facto operating systems. This Autonomic Network concept can benefit the productivity of smart applications in smart environment. Investigate the new strategies to improve the security management in Automation field. Future automation engineers will no longer be limited to the field of production. Many automation projects, for example, will be implemented within the so-called Smart City. In transportation, buildings, and health care, future automation projects will have closer proximity to people's everyday lives. The engineers' expertise in automation will be applied in many nontraditional fields. These innovations will drastically change people's lives, adding convenience. The automation system will become an important foundation for the future construction and operation of intellectualized and automated societies.

\section{ACKNOWLEDGMENT}

It give me immense pleasure to present paper on "Industrial Automation using Modern Controls , Monitoring ,data logging and development of training facility in college". These words of acknowledgment are my gratitude towards people who helped me throughout and without them successful completion of dissertation and paper. I have been very fortunate to work with Prof. Swapnil A. Namekar who has supervised the research carried out for my dissertation. .

\section{REFERENCES}

[1] Johann badinger, Natalia Moriz, Oliver niggemann, "Design of Industrial Automation Systems- Formal Requirements in the Engineering Process," 2013 IEEE 18th Conference on Emerging technologies \& Factory Automation(ETFA).

[2] Muhammad Chattal, Veer Bhan, Hina Madiha, Shoaib Ahmed Shaikh, "Industrial Automation \& Control Through Plc and Labview," 2019 2nd international Conference on Computing , Mathematics and Engineering technologies (ICoMET).

[3] K.V.M. Chadeev, N.I.Aristova, "Control Of Industrial Automationn," 2017 Tenth International Conference Management of Large-Scale System Development(MLSD).

[4] Rishabh Das, Sayantan Dutta, Anusree Sarkar , Kaushik Samanta, "Autoamtion of tank Level Using Plc and Establishment of Hmi by 
Scada," IOSR Journal of Electrical and Electronics Engineering (IOSR JEEE) Volume 7, Issue 2 (Jul.-Aug. 2013), PP 61-67.

[5] T. vignesh, J.Kirubakaran, "Automation Based Power Transmission Control Station Using Plc and Scada," IJISET- International Journal of Innovative Science, Engineering \& Technology, Vol.2 Issue 2, February 2015.

[6] Santhosh B. Belekar, "PLC SCADA Based Distribution Monitoring and Control," multidisciplinary journal of research in Engineering and Technology. 